\title{
THE ROLE OF VARIOUS MODALITIES IN BREAST IMAGING
}

\author{
Sachin Prasad Na*,Dana Houserkova ${ }^{\mathrm{a}}$ \\ ${ }^{a}$ Department of Radiology, Faculty of Medicine and Dentistry, Palacky University, Olomouc, Czech Republic \\ *e-mail:drsachinprasadn@yahoo.co.in
}

Received: September 7, 2007; Accepted: November 5, 2007

Key words: Mammography/Ultrasonography/MRI/Breast screening/Breast mass/Breast imaging

Background: Breast cancer is the most common type of cancer in women worldwide. Mammography is considered the "gold standard" in the evaluation of the breast from an imaging perspective. Apart from mammography, ultrasound examination and magnetic resonance imaging are being offered as adjuncts to the preoperative workup. Recently, other new modalities like positron emission tomography, $99 \mathrm{mTc}$-sestamibi scintimammography, and electrical impedance tomography (EIT) are also being offered. However, there is still controversy over the most appropriate use of these new modalities. Based on the literature, this review evaluates the role of various modalities used in the screening and diagnosis of breast cancer.

Methods and Results: Based on relevant literatures this article gives an overview of the old and new modalities used in the field of breast imaging. A narrative literature review of all the relevant papers known to the authors was conducted. The search of literatures was done using pubmed and ovid search engines. Additional references were found through bibliography reviews of relevant articles. It was clear that though various new technics and methods have emerged, none have substituted mammography and it is still the only proven screening method for the breast as of date.

Conclusion: From the literature it is clear that apropos modern radiology's impact on diagnosis, staging and patient follow-up, only one imaging technique has had a significant impact on screening asymptomatic individuals for cancer i.e.; low-dose mammography. Mammography is the only screening test proven in breast imaging. Positron emission tomography (PET) also plays an important role in staging breast cancer and monitoring treatment response. As imaging techniques improve, the role of imaging will continue to evolve with the goal remaining a decrease in breast cancer morbidity and mortality. Progress in the development and commercialisation of EIT breast imaging system will definitely help to promote other systems and applications based on the EIT and similar visualization methods. Breast ultrasound and breast magnetic resonance imaging (MRI) are frequently used adjuncts to mammography in today's clinical practice and these techniques enhance the radiologist's ability to detect cancer and assess disease extent, which is crucial in treatment planning and staging.

\section{INTRODUCTION}

Breast cancer is the second leading cause of cancer deaths in women today (after lung cancer) and the most common cancer in women. Its incidence increases dramatically with age. Although most breast cancers occur in women older than 50 years, 31 percent of women diagnosed with breast cancer between 1996 and 2000 were younger than 50 years ${ }^{1}$. The rate of increase is greatest in women younger than 50 years but most cases (approximately $80 \%$ of invasive cases) occur after age 50 years. Breast cancer commonly affects women older than 40 years of age; however, younger women can also be affected, especially those with a genetic predisposition ${ }^{1,2}$.

Important risk factors for female breast cancer include an early age at the onset of menarche, late age of menopause, a first full-term pregnancy after the age of 30 years, a history of pre-menopausal breast cancer in mother or sister, and personal history of breast cancer or sometimes even benign proliferative breast disease. Obesity, nulliparity, and urban residence have also been associated with an increased risk of breast cancer.
The earliest sign of breast cancer is an abnormality depicted on a mammogram, before the woman or her physician can feel it. When breast cancer has grown to the point where physical signs and symptoms appear, the patient feels a breast lump (usually painless) ${ }^{3}$. Other presentations include tenderness, skin irritation or dimpling, and nipple discharge or pain, scaliness, ulceration, or retraction. Breast pain is commonly due to benign conditions and not usually the first symptom of breast cancer ${ }^{3}$. Breast masses have a varied etiology, benign and malignant. Fibroadenoma is the most common benign breast mass and invasive ductal carcinoma is the most common malignancy. Efficient and accurate evaluation can maximize cancer detection and minimize unnecessary testing and procedures ${ }^{4}$.

\section{INITIAL EVALUATION}

\section{History}

A thorough patient history is necessary for the physician to identify risk factors for breast cancer. Some risk 
factors are well established, and others indicate probable or possible increased risk $^{5-9}$ (Tables 1 and 2).

\section{Physical examination}

Complete clinical breast examination (CBE) includes an assessment of breasts, the chest, axilla, and regional lymphatics. In premenopausal women, the CBE is best done the week following menses, when breast tissue is least engorged. With the patient in an upright position, the physician visually inspects the breasts, noting asymmetry, nipple discharge, obvious masses, and skin changes, such as dimpling, inflammation, rashes, and unilateral nipple retraction or inversion ${ }^{9}$. (Table 1 )

With the patient supine and one arm raised, the physician thoroughly palpates breast tissue on the raised-arm side in the superficial, intermediate, and deep tissue planes (i.e. the "triple touch" technique); axilla, supraclavicular area, neck, and chest wall, assessing the size, texture, and location of any masses ${ }^{9}$. The physician should note the size of the masses to document changes over time. Next, the physician should inspect the areola-nipple complex for any discharge. CBE sensitivity can be improved by longer duration (i.e. five to 10 minutes) and increased precision (i.e. using a systematic pattern, varying palpation pressure, and using three finger pads and circular motions $)^{10}$.

(Table 2) Benign masses generally cause no skin change and are smooth, soft to firm, and mobile, with well-defined margins. Diffuse, symmetric thickening, which is common in the upper outer quadrants, may indicate fibrocystic changes. Malignant masses generally are hard, immobile, and fixed to surrounding skin and soft tissue, with poorly defined or irregular margins ${ }^{10}$. However, mobile or nonfixed masses can be cancerous. Infections such as mastitis and cellulitis tend to be erythematous, tender, and warm to the touch. They may be more circumscribed if an abscess has formed. Similar symptoms may occur in patients with inflammatory breast cancer. Therefore, caution should be used in assessing patients with suspected breast infections.

\section{IMAGING METHODS}

\section{Mammography}

Mammography is the primary imaging modality for breast cancer screening and diagnosis. Mammography is X-ray imaging of the breasts designed to detect tumours or other abnormalities. Improvements over the last decade in the quality of performance and the reporting of mammography studies are the most important advances in breast imaging ${ }^{11}$.

With digital mammography, an image of the breast is recorded electronically rather than on film. The acquired digital image can be stored in computer memory and printed out later as a film or displayed and interpreted on a high-definition monitor. The ability to alter contrast and brightness permits further evaluation of abnormal areas to identify features diagnostic of benign and malignant disease ${ }^{12-14}$. Although the overall cancer-detection rate is similar in screen-field and full-field mammography, screenfield imaging has better image quality and fewer artefacts, and requires fewer patient recalls ${ }^{14}$.

In addition to its usefulness in telemammography, digital mammography may be more accurate than traditional mammography. Studies comparing the methods are underway. Potential new techniques include threedimensional imaging, lower-dose radiation, dual energy subtraction, contrast-enhancement imaging and computerassisted diagnosis ${ }^{15}$.

A standardized BI-RADS mammography report should include the reason(s) for doing the examination, the observed composition of the breast tissue, a description of the mammographic findings using the standardized lexicon, and a final assessment with management recommendation ${ }^{16}$. The overall density of a patient's breast tissue will help determine the sensitivity of mammography. Since breast cancers are radiodense (e.g. white on mammograms), radiolucent fat (dark grey-to-black on mammograms) provides an excellent background on which to see small cancers. On the other hand, dense fibroglandular breast tissue can obscure small cancers. Therefore, the standardized mammography report must include a statement about the overall composition of the breast in terms of the relative amounts of fatty and dense tissue. The breast composition can be characterized as one of four types: (1) the breast is almost entirely fatty (2) there are scattered islands of fibroglandular tissue (Fig. 1), (3) the breast tissue is heterogeneously dense (which may lower the sensitivity of mammography) and (4) the breast tissue is extremely dense (Fig. 2) (which will always lower the sensitivity of mammography). The standard lexicon for reporting abnormal findings on mammograms includes descriptors to indicate the likelihood of malignancy. Masses and calcifications are the most common abnormalities encountered on mammograms, and the radiographic appearances of these abnormalities are important clues to their etiology ${ }^{17,18}$.

The standardized report will also include one of six assessment categories, indicating the likelihood of malignancy and the radiologist's recommendations for management (Table 3) Category "0", or "Incomplete: Need additional imaging evaluation," is usually used for a screening examination in which a definitive recommendation cannot be made until more information is obtained. The additional information that is needed might be an earlier comparison mammogram or a subsequent study, such as a problem-solving (diagnostic) mammogram or ultrasonogram. Once the individual patient work-up has been completed, the resulting examination will then be assigned to one of five other assessment categories as listed in Table 3.

Screening mammography: Screening mammography is used to detect breast changes in women who have no signs or symptoms or observable breast abnormalities. The goal is to detect cancer before any clinical signs are noticeable. This usually requires at least two mammograms from different angles of each breast. 
Table 1. Relevant History in Women with Palpable Breast Masses.

\begin{tabular}{|c|c|}
\hline $\begin{array}{l}\text { Breast lump characteristics } \\
\text { Changes in size over time } \\
\text { Change relative to menstrual cycle } \\
\text { Duration of mass } \\
\text { Pain or swelling } \\
\text { Redness, fever, or discharge } \\
\text { Diet and medication } \\
\text { Current medications } \\
\text { History of hormone therapy } \\
\text { Family history } \\
\text { History of breast disease } \\
\text { Relationship to patient } \\
\text { Relative's age at onset }\end{array}$ & $\begin{array}{l}\text { Medical and surgical history } \\
\text { Personal history of breast cancer } \\
\text { Previous breast masses and biopsies } \\
\text { Recent breast trauma or surgery } \\
\text { Recent radiation therapy or chemotherapy } \\
\text { Personal characteristics } \\
\text { Age at first childbearing } \\
\text { Age at menarche } \\
\text { Age at menopause } \\
\text { Current age } \\
\text { Current lactation status } \\
\text { History of breastfeeding } \\
\text { Number of children } \\
\text { Social history } \\
\text { Radiation and chemical exposure } \\
\text { Smoking }\end{array}$ \\
\hline
\end{tabular}

Table 2. Risk Factors for Breast Cancer.

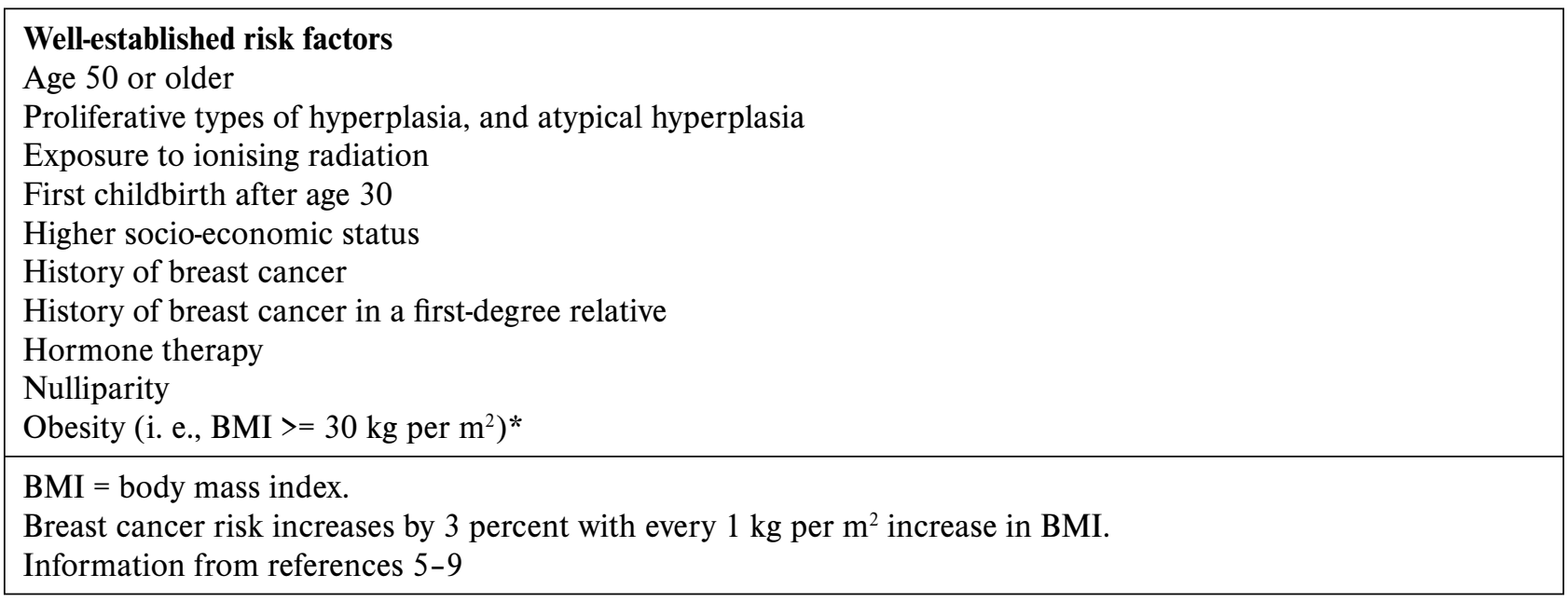

Table 3. Mammography Final Assessment Categories.

\begin{tabular}{|c|l|l|}
\hline Category & \multicolumn{1}{|c|}{ Assessment } & \multicolumn{1}{c|}{ Description } \\
\hline $\mathbf{0}$ & Incomplete assessment & Additional imaging work-up needed. \\
\hline $\mathbf{1}$ & Negative & There is nothing to comment on. \\
\hline $\mathbf{2}$ & Benign finding & A definitely benign finding described. \\
\hline $\mathbf{3}$ & Probably benign finding & $\begin{array}{l}\text { Very high probability of being benign. Short-term follow-up } \\
\text { recommends establishing stability. }\end{array}$ \\
\hline $\mathbf{4}$ & Suspicious abnormality & $\begin{array}{l}\text { Not characteristic, but has reasonable probability of being } \\
\text { malignant. Biopsy should be considered. }\end{array}$ \\
\hline $\mathbf{5}$ & Highly suggestive of malignancy & $\begin{array}{l}\text { High probability of being cancer. Malignancy } \\
\text { Appropriate action should be taken. }\end{array}$ \\
\hline
\end{tabular}




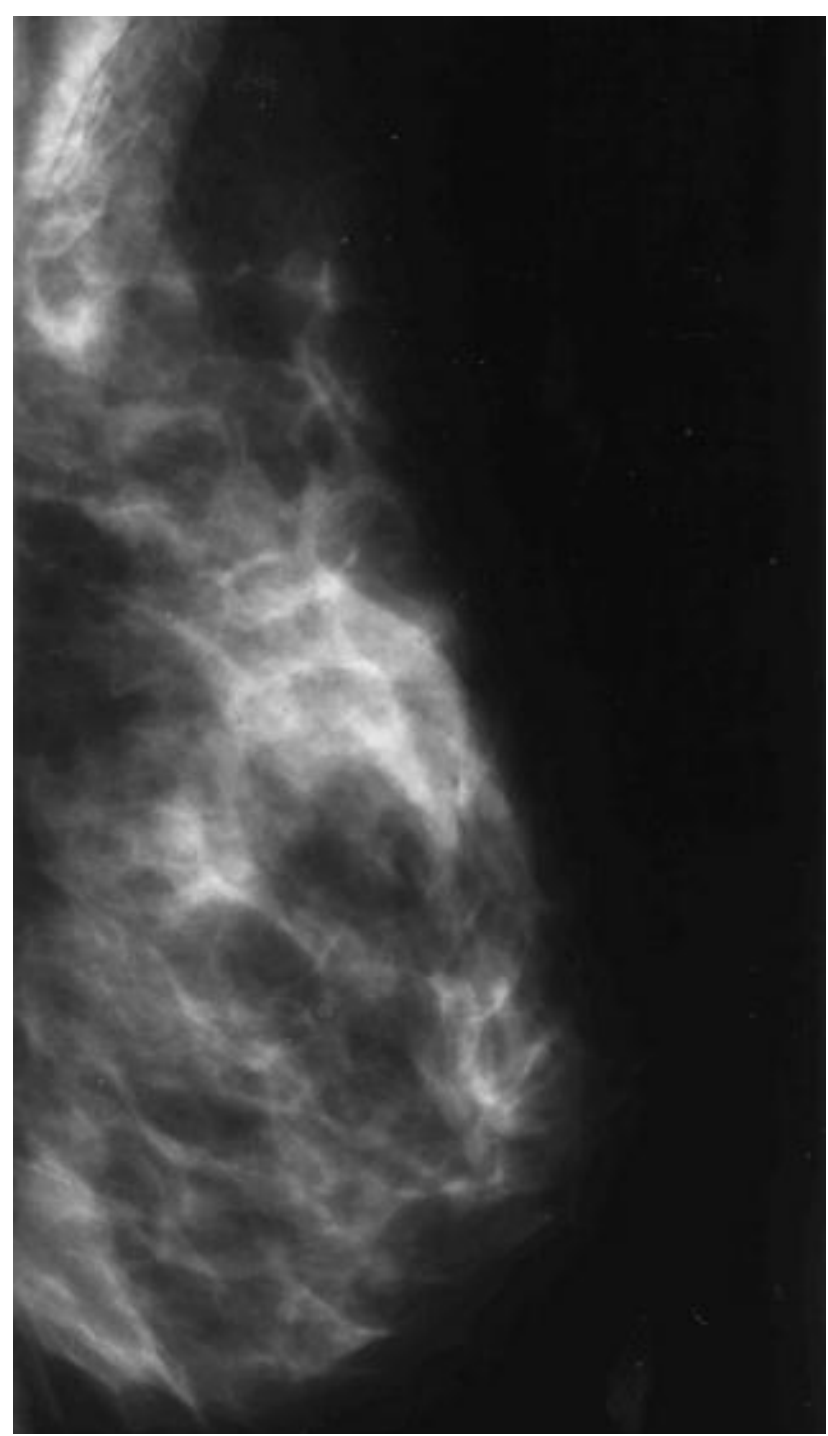

Fig. 1. Primarily fatty breast with scattered islands of fibroglandular tissue. Mammography has high sensitivity in this type of breast.

Diagnostic mammography: Diagnostic mammography can help physicians determine whether a lesion is potentially malignant, and it also screens for occult disease in surrounding tissue. Diagnostic mammography is used to investigate suspicious breast changes such as a breast lump, breast pain, an unusual skin appearance and nipple thickening or nipple discharge ${ }^{18}$. It is also used to evaluate abnormal findings on a screening mammogram. Additional images can be made from other angles or focus on areas of concern at higher magnification.

\section{Ultrasonography}

Ultrasonography is the most important adjunctive imaging modality for breast cancer diagnosis. Over the years, it has also undergone significant improvements that have extended its utility for breast imaging. The traditional role of ultrasonography was to differentiate cysts from solid masses $^{19,20}$. Two of the most important clinical advances in breast US have been the development of criteria that

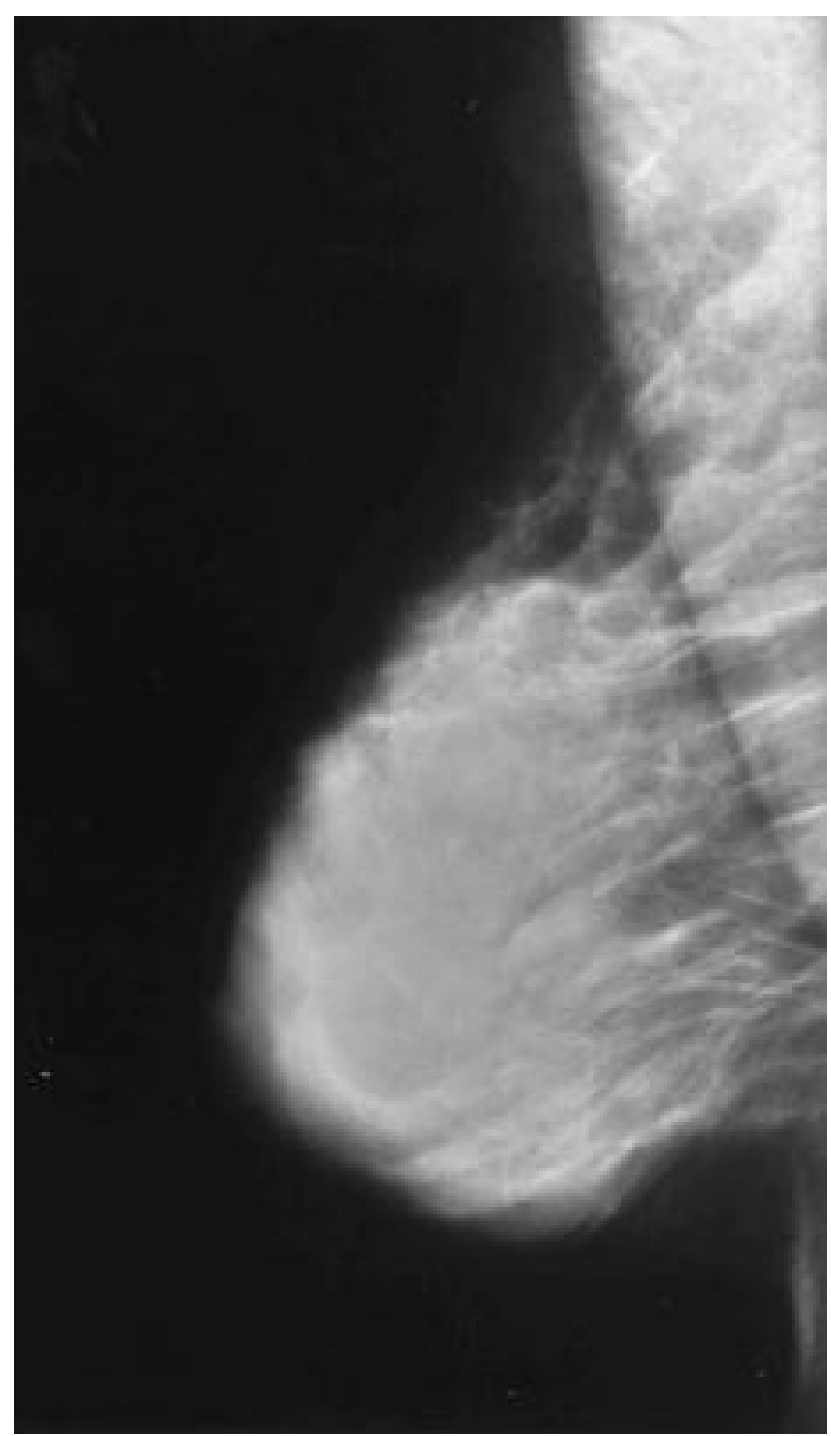

Fig. 2. Extremely dense breast. The sensitivity of mammography is limited, due to dense tissue, which could obscure a carcinoma.

allow improved benign/malignant differentiation of solid breast lesions and the use of US to guide interventional procedures such as needle aspirations, core-needle biopsies, and pre-biopsy needle localizations of breast masses or calcifications ${ }^{21,22}$. Ease of use and real-time imaging capability make breast ultrasound a method of choice for guiding breast biopsies and other interventional procedures. Frequent advances in transducer design, electronics, computers, and signal processing have improved the quality of ultrasound images to the extent that sonography is now a major mode of imaging for the clinical diagnosis of breast cancer. Breast ultrasound is routinely used for differentiating cysts and solid nodules with high specificity. In combination with mammography, ultrasound is used to characterize solid masses as benign or malignant. Characteristic ultrasonographic features of a cyst are its round or oval shape, circumscribed margins, anechoic interior, and enhanced distal echoes posterior to the cyst (FIG-3). Continuing improvements in ultrasonography 


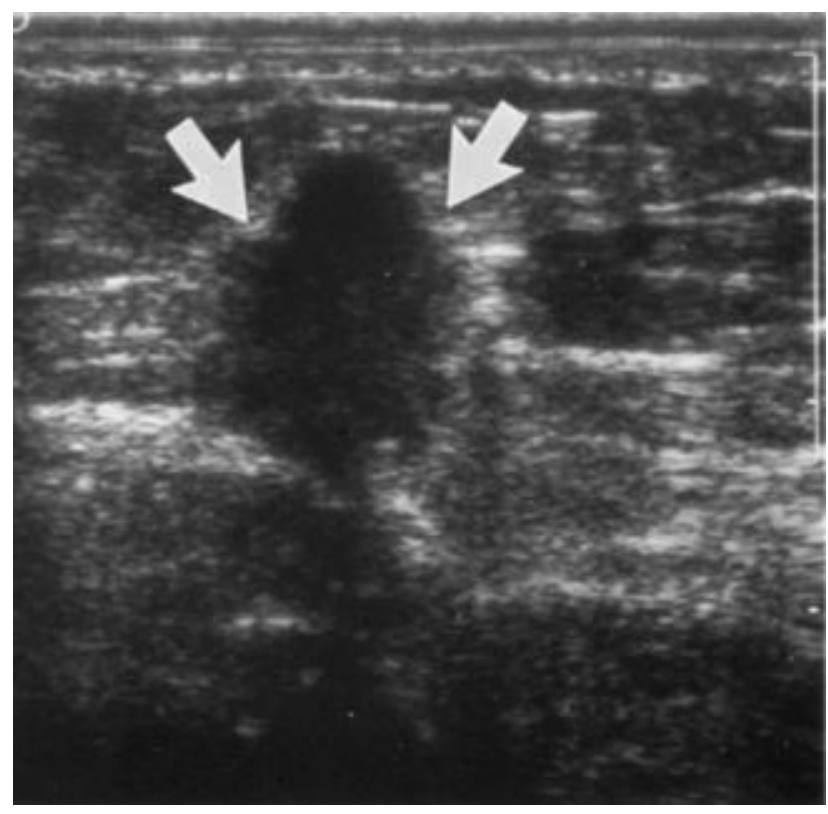

Fig. 3. Ultrasonogram of carcinoma. This mass (arrows) has features suggesting malignancy: ill-defined margins, height equal to or greater than width, and low-level heterogeneous internal echoes.

equipment have led to the identification of additional features that may help to differentiate benign from malignant solid masses ${ }^{23}$. These include the shape, margins, and echogenicity of a breast mass (Fig. 4). It remains to be seen whether these signs are reliable enough to avoid the need for biopsy of solid masses that have "benign" ultrasound features. Ultrasonography can effectively distinguish solid masses from cysts, which account for approximately 25 percent of breast lesions ${ }^{24,25}$. When strict criteria for cyst diagnosis are met, ultrasonography has a sensitivity of 89 percent and a specificity of 78 percent in detecting abnormalities in symptomatic women ${ }^{18}$. Recurrent or complex cysts may signal malignancy; therefore, further evaluation of these lesions is required ${ }^{26}$. Although ultrasonography is not considered a screening test, it is more sensitive than mammography in detecting lesions in women with dense breast tissue ${ }^{25,26}$. It is useful in discriminating between benign and malignant solid masses ${ }^{25,26}$, and it is superior to mammography in diagnosing clinically benign palpable masses (i.e. up to 97 percent accuracy versus 87 percent for mammography) (ref. ${ }^{26)}$. Ultrasound can be used in younger women and women with breast implants but cannot always detect micro calcifications. It is entirely a safe method, and can be used regularly for these purposes. The effectiveness depends on the ability of the radiologist performing the test. Another disadvantage is that it cannot differentiate between certain solid masses and it has poor ability to visualise deep lesions. Breast ultrasound is used in many forms. B-mode is the most common form of imaging for the breast, although compound imaging and harmonic imaging are being increasingly applied to better visualize

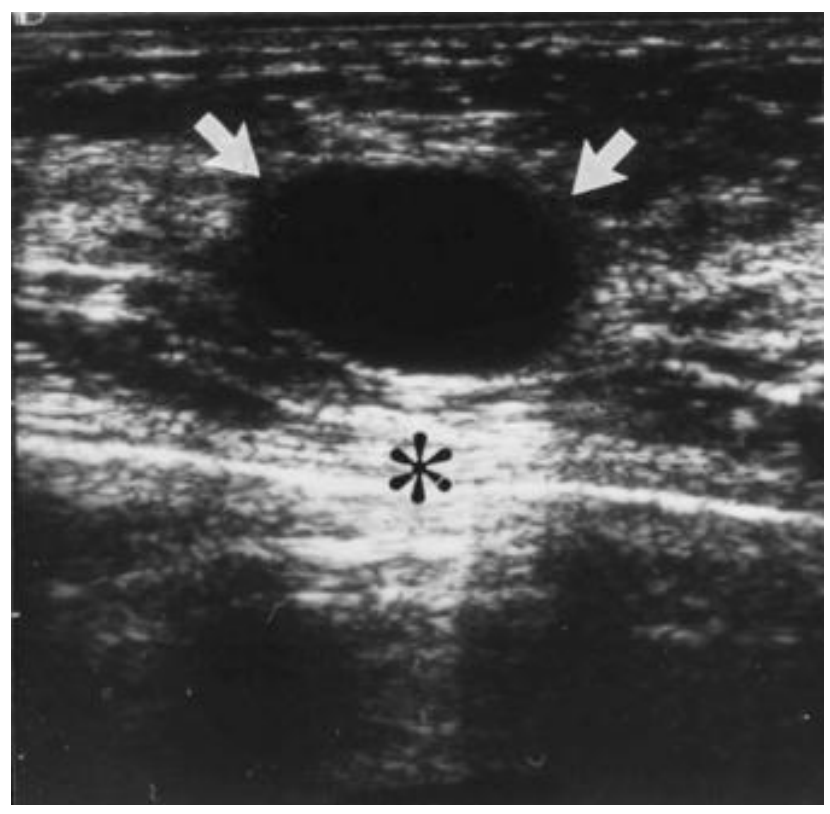

Fig. 4. Ultrasonogram of a cyst. The cyst (arrow) is characterized by an oval or round shape, circumscribed margins, absence of internal echoes (anechoic interior), clearly defined posterior wall, and enhancement of distal echoes $(*)$

breast lesions and to reduce image artefacts. These developments, together with the formulation of a standardized lexicon of solid mass features, have improved the diagnostic performance of breast ultrasound ${ }^{26,27}$.

Doppler ultrasound During a breast ultrasound examination the sonographer or physician performing the test may use Doppler techniques to evaluate blood flow or lack of flow in any breast mass. With the development of ever more sensitive color doppler and power Doppler ultrasound machines the ability to detect flow in solid masses and even to differentiate that flow also has added another level of sophisication to ultrasound analysis of breast masses. Color doppler does not discriminate completely between benign and malignant masses; the presence of signals in a lesion that is otherwise thought to be benign should prompt a biopsy while the absence of signals in an indeterminate lesion is reassuring. Therefore color doppler is now widely established as a useful addition to breast imaging and dynamic features of ultrasound that are useful in breast diagnosis ${ }^{27}$.

\section{Magnetic resonance imaging}

Magnetic resonance imaging (MRI) is a non-invasive, usually painless medical test that helps physicians diagnose and treat medical conditions. MRI does not use ionising radiation (x-rays). MRI of the breast offers valuable information about breast conditions that cannot be obtained by other imaging modalities, such as mammography or ultrasound. MRI of the breast is not a replacement for mammography or ultrasound imaging but rather a supplemental tool for detecting and staging breast cancer and other breast abnormalities ${ }^{28}$. 
Medical studies are currently being conducted to determine whether MRI can contribute to the early detection and prevention of deaths from breast cancer. New pulse sequences in MRI combined with contrast enhancement kinetic perfusion curves have greatly enhanced detection of mammographically occult cancers. Magnetic resonance imaging (MRI) is being studied to determine its usefulness in diagnosing breast masses. Gadolinium contrast is used to enhance the vascularity of malignant lesions. Although MRI is highly sensitive ( 85 to 100 percent), it lacks specificity (47 to 67 percent) (ref. ${ }^{28,29}$ ). MRI is inferior to mammography in detecting in situ cancers and cancers smaller than $3 \mathrm{~mm}$, and it provide no cost benefit over excisional biopsy for verifying malignancy ${ }^{28,29}$. Research suggests two potential roles for MRI in breast mass diagnosis: evaluating patients with silicone breast implants and assessing patients in whom evaluation by ultrasonography and mammography is problematic ${ }^{30}$. The latter group includes patients who have had breast-conserving surgery; patients with known carcinoma in whom multifocal, ipsilateral, or contralateral disease must be ruled out, patients with axillary metastasis and an unknown primary, patients with extensive postoperative scarring, and patients with extremely dense parenchyma ${ }^{30-32}$. Although MRI improves detection of early breast cancers in carriers of BRCA mutations, it has a lower specificity than mammography, which requires additional evaluations. It also has limited sensitivity in detecting ductal carcinoma in situ. MRI of the breast cannot always distinguish between cancer and benign breast disease (such as fibroadenomas), leading to a false positive result ${ }^{31}$.

A benefit of MRI is that it can easily acquire direct views of the breast in any orientation while mammography requires re-orientation of the breast and mammography system for each view desired. An MRI exam of the breast typically takes between 30 and 60 minutes. The injection of a contrast agent can further the ability of MRI to detect a specific feature or in case of dynamic contrastenhancement MRI study, the functionality of tissue ${ }^{32}$. The contrast agents used are paramagnetic agents with gadolinium (Gd-DTPA) being the most common. The effect of this agent is to shorten the relaxation time of local spins causing a decrease in signal in T2 weighted images and an increase in T1 weighted images. The increased vascularity of tumours produces a preferential uptake of contrast agent and the technique can be used to improve their contrast from surrounding normal tissue ${ }^{32,33}$. Furthermore if MRI scans are repeatedly acquired following the contrast injection, the dynamic nature of contrast uptake can be examined, which may improve the differentiation of benign and malignant disease. This is called dynamic contrast-enhancement $\mathrm{MRI}^{34}$.

A few advantages of MRI of the breast are that it can be used in women with denser breasts, it is non-ionising, it can take images in any orientation, it can determine multi-focal cancers and it is useful in determining if the cancer has spread to the chest wall. It can also be used to check for recurrence of cancer in women who have undergone lumpectomy. MRI can assess if a newly inverted nipple is a sign of retroareolar cancer, it can see breast implants and look for ruptures. The disadvantages are that it is expensive, requires injection of a contrast agent for functional imaging. Specificity can be limited, it is highly sensitive to small abnormalities, and cannot image calcifications and can induce feelings of claustrophobia. It has long scan times in comparison to x-ray mammography ${ }^{35}$.

\section{Positron emission tomography (PET)}

Positron emission tomography (PET scan) is one of the newest forms of imaging tests. PET is a type of nuclear medicine study. A tiny amount of radioactive substance is injected into an arm vein. This substance gives off small amount of radiation that is detected by a special PET scanner to form an image. The most commonly used substance in this test is fluorodeoxyglucose (FDG), which is a type of sugar. It is an effective means of predicting response to neoadjuvant chemotherapy in patients with breast can$\operatorname{cer}^{36}$. It goes to places in the body where the cells are most active, especially highlighting cancerous tissue and ensure that the most appropriate form of treatment is selected ${ }^{36}$. A PET scan may be combined with computed tomography (CT) to provide both an anatomical and functional view of the suspect cells. With all this information, doctors can better differentiate between healthy and cancerous cells, even when the cancer is too small to detect by conventional imaging. This is particularly important when looking to see if cancer has spread ("metastasized") from the breast to other parts of the body ${ }^{37}$. PET is being used to detect metastatic disease (cancer spread) and has been successful in that role. The PET scan is not currently used for primary breast cancer detection because it does not reliably detect tumors smaller than $5-10 \mathrm{~mm}$, but research is being done to improve the accuracy of this test.

\section{Electrical impedance tomography (EIT)}

EIT is a relatively new imaging method that has evolved over the past 20 years. It has the potential to be of great value in clinical diagnosis; however, EIT is a technically difficult problem to solve in terms of developing hardware for data capture and the algorithms to reconstruct the images ${ }^{38}$. "Electrical Impedance Computerized Mammograph MEIK" is an EIT system for breast diagnostics approved for clinical usage in Russia. The system realizes 3D imaging approach using flat matrix with 256 electrodes. An EIT system utilizes an array of electrodes to apply currents to an imaging domain and measures the resulting voltages on the periphery ${ }^{38}$. The measurement results are then input to a reconstruction algorithm to produce an image of the impedance distribution inside the domain. Electrical impedance imaging scans the breast for electrical conductivity based on the idea that breast cancer cells conduct electricity better. It involves passing a very small electrical current through the body and detecting it on the skin of the breast with a small probe. The test does not use radiation and does not require breast compression. This test has received approval by the US Food and Drug Administration to be used as a diagnostic aid to mammography ${ }^{39}$. However, it has not undergone 
enough clinical testing to recommend its use in breast cancer screening. Some evidence has been found that malignant breast tumours have lower electrical impedance than surrounding normal tissues. Although the separation of malignant tumours from benign lesions based on impedance measurements needs further investigation, electrical impedance could be used as an indicator for breast cancer detection. The conductivity and resistance of breast tumours are known to differ significantly from those of normal breast tissues; EIT is being studied as a modality for breast cancer imaging to exploit these differences. EIT and T-scan Electrical Impedance imaging is based on the idea that tissues have different conductivities depending on their cell structure and pathology ${ }^{39}$. Cancerous tissue causes alterations in the intracellular and extra cellular fluid compartments, cell membrane surface area, ionic permeability, and membrane associated water layers. These histological biochemical changes within the cancerous tissue give rise to measurable changes in tissue electrical impedance ${ }^{39,40}$. When a small alternating current is placed across the breast, the increase in electrical conductance and capacitance of the cancer tissue distorts the electric field within the breast and the resulting impedance map can be used to highlight a malignant area. Among non-invasive imaging techniques, EIT is a technique offering low cost, but low resolution, images. Inaccurate modelling of the regionally varying electrode-skin contact impedance and poor signal-to-noise ratio causes its main limitation. At present, X-ray mammography is the primary standard imaging modality used for breast cancer screening in clinical practice, so it is desirable to study EIT in the geometry of mammography.

\section{Thermography}

Thermography is based on the principle that metabolism and blood vessel proliferation in both pre-cancerous tissue and the area surrounding a developing breast cancer is almost always higher than in normal breast tissue. Developing tumours increase circulation to their cells by enlarging existing blood vessels and creating new ones in a process called vascularisation. This process frequently results in an increase in regional surface temperatures of the breast. Thermography uses ultra-sensitive infrared cameras and PCs to generate high-resolution diagnostic images of these temperature variations ${ }^{41}$. Although thermography is an appealing method of screening for breast cancer, research over the past 20 years has failed to produce a system that is reliable for such a purpose and so thermography is not widely used ${ }^{41}$. It should also be noted that attenuation of infrared radiation in tissue is high. For this reason, thermography will only ever be able to provide information on the surface temperature variations and so no depth information will be available. This is a severe limitation of thermography in detecting breast cancer.

\section{Galactography}

In this X-ray procedure, the milk duct may be dilated and a fine plastic tube is placed into the opening of the duct in the nipple. A small amount of contrast medium is injected, which outlines the shape of the duct on an $\mathrm{x}$-ray image and shows whether a mass is present inside the duct. While mammography and MRI are excellent ways to image the breast, they cannot visualize inside the breast's milk ducts. A ductogram or galactogram is sometimes helpful for determining the cause of nipple discharge. The most common use of galactography is to evaluate a woman who has a bloody or clear discharge from her breast nipple and an otherwise normal mammogram. The procedure normally takes between 30 minutes and an hour. The dilation of the milk duct can sometimes be uncomfortable; however it is usually not painful. The nipple may be squeezed to identify the milk duct with the discharge. The advantage of galactography is that it can find small cancerous and non-cancerous tumors that cannot be identified in any other way so that they may be removed at an early stage. The limitation of ductography is that, if there is no discharge at the time of the exam, the duct cannot be identified, so the test cannot be performed. In addition, some ducts are quite small and cannot be dilated. If the incorrect duct is injected, a wrong diagnosis can be made.

\section{Technetium sestamibi scan (scintimammography)}

A compound known as technetium sestamibi has been studied to help detect breast cancer. This test is marketed under the trade name Miraluma. In this procedure, a small amount of the radioactive substance is injected into an arm vein. A special camera then records where radiation has accumulated in the breasts. This procedure cannot distinguish cancer from noncancerous lesions as accurately as routine mammography, and is not used as an initial screening test. Some radiologists believe it is sometimes useful in looking at suspicious areas found by regular mammograms. However, studies of the test have yielded varying results. The general consensus is that this test is less sensitive than mammography, especially when the tumour is still small and most likely to be curable. For these reasons, the exact role of this test remains unclear ${ }^{42}$. Current research is aimed at improving the technology and evaluating its use in specific situations such as in the dense breasts of younger women. Nuclear medicine breast imaging or scintimammography is sometimes used alongside x-ray mammography in the diagnosis of breast disease as it has the ability to determine if a located lesion is malignant. This investigation of the breast usually takes between 45 and 60 minutes. To perform an exam the radioactive tracer ( $\mathrm{Tc}-99 \mathrm{~m}$ sestamibi) is injected into the patients arm. The patient is then asked to lie face down on a special table and suspend her breast through a hole. Approximately five minutes after the injection, images of the breast are taken from several angles using a gamma camera. A few advantages of this method are that it can be used on patients with dense breasts. It can image large palpable lesions that do not appear using other imaging modalities whilst it is $90 \%$ accurate for abnormalities over $1 \mathrm{~cm}$ it is only $40-60 \%$ accurate for smaller abnormalities. It can be used to test tissue remaining from mastec- 
tomy, it can be used to check for metastases in the axillary lymph nodes and it is able to determine multifocal breast cancers $^{43}$. Disadvantages are that it involves injecting a substance into a patient. It is invasive and long examination time.

\section{Computed tomography}

Spiral CT is useful for elucidating problems in the diagnosis of breast lesions. Its advantages consist in the speed of the method, comfort for the patient, absence of movement artefacts, easy standardization and wide applicability. Dynamic contrast-enhanced CT of the breast has been found to be effective for the detection of intraductal extension of breast carcinoma and is thought to be useful in the preoperative assessment of indications of breast-conserving surgery $^{44}$. The lesions appear attenuating compared with fatty background, and they show early enhancement on arterial phase on dynamic contrast-enhanced CT. CT is usually not the first modality to be used in imaging breast cancer, but it may be used as an adjuvant for monitoring spread. Although it involves some exposure to radiation, it should be considered in patients in whom MRI is contraindicated. Three-dimensional (3D) helical CT can provide good information about the spread of breast cancer and could be an alternative to 3D MRI for preoperative examination of breast cancer ${ }^{44}$. In vitro high-resolution helical CT can depict the internal structure of small nodes. Morphologic changes detected on helical CT help distinguish benign from malignant nodes. Tumours appear as dense lesions on CT and usually shows early contrast enhancement similar to that seen with dynamic MRI. CT is less sensitive than mammography for detecting microcalcification when it is the sole manifestation of early cancer ${ }^{45}$.

\section{INTERVENTIONAL METHODS}

A suspicious area in the breast may be detected by physical exam, mammogram or another imaging method or by some combination of these modalities. But regardless of the method of detection, the presence of cancer can only be confirmed by a biopsy, in which a sample of cells or tissue is removed and looked at under the microscope. For suspicious areas that cannot be felt, imaging tests may be done to ensure the right area is biopsied. A breast biopsy helps identify any abnormalities in the cells that make up breast lumps or other unusual breast changes, and it can help determine whether or not a surgery is needed or any other treatment.

\section{Open Surgical Biopsy}

Open surgical biopsy was a traditional standard method of breast biopsy. For years, excisional biopsy was a woman's only option. Surgical biopsy requires 1.5 to 2.0 inch incision (approximately $3.8 \mathrm{cms}$ to $5.1 \mathrm{cms}$ ) in the breast. It may leave a scar at the incision site. However today, many patients are candidates for less invasive biopsy procedures such as vacuum assisted biopsy (Mammotome) or core needle biopsy.

\section{Wire localization}

Wire localization is a procedure used to guide a surgical (excisional) breast biopsy of a small mass that would be hard for the surgeon to locate. It can also be useful with areas that look suspicious on the x-ray (due to calcifications, for example) but do not have a distinct lump. After numbing the area with local anaesthetic, hollow needles thinner than that used for drawing blood, are inserted into the breast and X-rays are used to guide the needle to the suspicious area. A thin wire is then inserted through the center of the needle. A small hook at the end of the wire keeps it in place. The hollow needle is then removed. The surgeon uses the wire as a guide to locate the abnormal area to be removed.

\section{Needle Biopsy}

Many suspicious breast abnormalities can now be diagnosed without surgery by using needle biopsy. There are 2 types of needle biopsies:

Fine needle aspiration (FNA) - FNA biopsy uses a very thin, hollow needle to remove fluid and tiny fragments of tissue. This procedure involves inserting a thin needle into the breast to remove cells from a lump. These cells are then examined under a microscope. Local anesthesia may be given. This test may be done to determine whether a lump is solid or is a fluid-filled cyst. A cyst will collapse and disappear after the fluid is removed. If the lump is not a cyst, another type of biopsy may be done.

Core needle biopsy (CNB) - A core needle biopsy is a percutaneous procedure that involves removing small samples of breast tissue using a hollow "core" needle. For palpable lesions, this is accomplished by fixing the lesion with one hand and performing a free hand needle biopsy with the other. In the case of non-palpable lesions, stereotactic mammography or ultrasound image guidance is used. Stereotactic mammography involves using computers to pinpoint the exact location of a breast mass based on mammograms taken from two different angles. The computer coordinates will help the physician to guide the needle to the correct area in the breast. With ultrasound, the radiologist or surgeon will watch the needle on the ultrasound monitor to help guide it to the area of concern. The needle used during core needle biopsy is larger than the needle used with FNA (usually a 16, 14, or 11 gauge needle is used with the core needle biopsy procedure). The core needle biopsy needle also has a special cutting edge. Core needle biopsy usually allows for a more accurate assessment of a breast mass than FNA (if the sample is found to be solid or cloudy, suspicious-looking fluid) because the larger core needle usually removes enough tissue for the pathologist to evaluate abnormal cells in relation to the surrounding small sample of breast tissue taken in the specimen. Nevertheless, core needle biopsy like FNA, only removes samples of a mass and not the entire area of concern. Therefore, it is possible that a more serious diagnosis may be missed by limiting the sampling of a lesion (abnormality). A relatively new biopsy procedure called vacuum assisted breast biopsy is able to remove approximately twice the amount of breast tissue compared 
with core needle biopsy while still offering the patient a minimally invasive breast biopsy procedure.

\section{Stereotactic vacuum assisted biopsy}

The relatively new vacuum-assisted breast biopsy is a percutaneous procedure that relies on stereotactic mammography or ultrasound imaging. Stereotactic mammography involves using computers to pinpoint the exact location of a breast mass based on mammograms taken from two different angles. The computer coordinates will help the physician to guide the needle to the correct area in the breast. With ultrasound, the radiologist or surgeon will watch the needle on the ultrasound monitor to help guide it to the area of concern. The patient will either by positioned in the upright or prone (face down) position for a vacuum-assisted biopsy. Vacuum-assisted biopsy is a minimally invasive procedure that allows for the removal of multiple tissue samples. However, unlike core needle biopsy, which involves several separate needle insertions to acquire multiple samples, the special biopsy probe used during vacuum-assisted biopsy is inserted only once into the breast through a small skin nick made in the skin of the patient's breast. Two new stereotactic biopsy methods can remove more tissue than a core biopsy.

\section{The Mammotome (brand name)}

It is also known as vacuum-assisted biopsy. For this procedure the skin is numbed and a small incision (about L' inch) is made. A probe is inserted through the incision into the abnormal area of breast tissue. A cylinder of tissue is suctioned into the probe then a rotating knife within the probe cuts the tissue sample from the rest of the breast ${ }^{46}$. The Mammotome procedure is done as an outpatient. No stitches are needed and there is minimal scarring. This method usually removes about twice as much tissue as core biopsies.

The ABBI method (ABBI also known as large core biopsy is a brand name that stands for Advanced Breast Biopsy Instrumentation).

It is a surgical technique that involves removing an entire intact breast lesion under image guidance. While the ABBI procedure tends to be less invasive than the traditional open surgical biopsy, this technique has not gained widespread acceptance. It uses a probe with a rotating circular knife and thin heated electrical wire to remove a large cylinder of abnormal tissue $\mathrm{e}^{47}$.

In some centres, the biopsy is guided by an MRI, which locates the tumours, plots its co-ordinates, and aims the stereotactic biopsy device into the tumour. ABBI requires the removal of a significant portion of normal breast tissue just to reach the lesion. Critics of large core biopsy $(\mathrm{ABBI})$ say that the procedure removes unnecessary normal breast tissue and does not remove an adequate margin of tissue around the breast lesion for laboratory analysis. For these reasons, large core biopsy (ABBI) is not widely embraced in the medical community. Vacuum-assisted biopsy may be a viable alternative to large core biopsy (ABBI) in some instances.

\section{CONCLUSION}

The literature shows that the only radiological technique that has had significant impact on the diagnosis, staging and patient follow-up in the case of screening asymptomatic breasts for cancer is low-dose mammography. Mammography is the only reliable screening test proven in breast imaging. Although it is an effective screening tool, it does have limitations, particularly in women with dense breasts. Recent studies show that Computer aided detection, breast ultrasound and breast magnetic resonance imaging (MRI) are frequently used adjuncts to mammography in today's clinical practice and these techniques enhance the radiologist's ability to detect cancer and assess disease extent, which is crucial in treatment planning and staging.

Positron emission tomography (PET) also plays an important role in staging breast cancer and monitoring treatment response. As imaging techniques improve, the role of imaging will continue to evolve with the goal remaining a decrease in breast cancer morbidity and mortality. The progress in the development and commercialisation of EIT breast imaging system will definitely help to promote other systems and applications based on the EIT and similar visualization methods.

At present $\mathrm{x}$-ray mammography is the most commonly used breast-imaging technique and is thus the "gold standard" in the evaluation of the breast from an imaging perspective.

\section{REFERENCES}

1. National Cancer Institute. SEER 1973-2001 public-use data. Accessed online October 14, 2004, at: http://seer.cancer.gov/publicdata/.

2. Madigan MP, Ziegler RG, Benichou J, Byrne C, Hoover RN. Proportion of breast cancer cases in the United States explained by well-established risk factors. J Natl Cancer Inst 1995; 87:1681-5.

3. Boyd NF, Jensen HM, Cooke G, Han HL, Lockwood GA, Miller AB. Mammographic densities and the prevalence and incidence of histological types of benign breast disease. Reference Pathologists of the Canadian National Breast Screening Study. Eur J Cancer Prev 2000; 9:15-24.

4. Schoonjans JM, Brem RF. Fourteen-gauge ultrasonographically guided large-core needle biopsy of breast masses. J Ultrasound Med 2001; 20:967-72.

5. Van Ongeval Ch. Department of Radiology, KULeuven, UZ Gasthuisberg, Leuven, Belgium. Digital mammography for screening and diagnosis of breast cancer: an overview. JBR-BTR. 2007 May-Jun; 90(3):163-6.

6. Newcomb PA, Titus-Ernstoff L, Egan KM, Trentham-Dietz A, Baron JA, Storer BE, et al. Postmenopausal estrogen and progestin use in relation to breast cancer risk. Cancer Epidemiol Biomarkers Prev 2002; 11:593-600.

7. Weiss LK, Burkman RT, Cushing-Haugen KL, Voigt LF, Simon MS, Daling JR, et al. Hormone replacement therapy regimens and breast cancer risk (1). Obstet Gynecol 2002; 100:1148-58.

8. Key TJ, Appleby PN, Reeves GK, Roddam A, Dorgan JF, Longcope $\mathrm{C}$, et al. Body mass index, serum sex hormones, and breast cancer risk in postmenopausal women. J Natl Cancer Inst 2003; 95:121826.

9. Barton MB, Harris R, Fletcher SW. The rational clinical examination. Does this patient have breast cancer? The screening clini- 
cal breast examination: should it be done? How? JAMA 1999; 282:1270-80.

10. Campbell HS, Fletcher SW, Pilgrim CA, Morgan TM, Lin S. Improving physicians' and nurses' clinical breast examination: a randomized controlled trial. Am J Prev Med 1991; 7:1-8.

11. Leichter I, Buchbinder S, Bamberger P, Novak B, Fields S, Lederman R. Quantitative characterization of mass lesions on digitized mammograms for computer-assisted diagnosis. Invest Radiol 2000; 35:366-72.

12. Obenauer S, Luftner-Nagel S, von Heyden D, Munzel U, Baum F, Grabbe E. Screen film vs full-field digital mammography: image quality, detectability and characterization of lesions [published correction appears in Eur Radiol 2002; 12:2388]. Eur Radiol 2002; 12:1697-702.

13. Lewin JM, Hendrick RE, D'Orsi CJ, Isaacs PK, Moss LJ, Karellas A, et al. Comparison of full-field digital mammography with screenfilm mammography for cancer detection: results of 4,945 paired examinations. Radiology 2001; 218:873-80.

14. Fischer U, Baum F, Obenauer S, Luftner-Nagel S, von Heyden D, Vosshenrich R, et al. Comparative study in patients with microcalcifications: full-field digital mammography vs screen-film mammography. Eur Radiol 2002; 12:2679-83.

15. Hrung JM, Sonnad SS, Schwartz JS, Langlotz CP. Accuracy of MR imaging in the work-up of suspicious breast lesions: a diagnostic meta-analysis. Acad Radiol 1999; 6:387-97.

16. Farewell VT, Bulbrook RD, Hayward JL. Risk factors in breast cancer: A prospective study in the island of Gnernsy, in early diagnosis of Breast cancer. New York: E. Grandmann and L. Beck Gustav Fisher Verlag Stuttgart, 1978: 43-51, 1978.

17. Kriege M, Brekelmans CT, Boetes C, Besnard PE, Zonderland HM, Obdeijn IM, et al. Efficacy of MRI and mammography for breast-cancer screening in women with a familial or genetic predisposition. N Engl J Med 2004; 351:427-37.

18. Baines CJ, Miller AB. Mammography versus clinical examination of the breasts. J Natl Cancer Inst Monogr 1997; (22):125-9.

19. Kopans DB. What is a useful adjunct to mammography? Radiology 1986; 161: 560-561.

20. Joensuu H, Asola R, Holli K, Kumpulainen E, Nikkanen V, Parvinen LM. Delayed diagnosis and large size of breast cancer after a flase negative mammogram. Eur J Cancer 1994; 30:1299 -1302 .

21. Orel SG, Schnall MD, Livolsi VA, Troupin RH, Suspicious breast lesion: MRI with radiologic - pathologic correlation. Radiology 1994; 190:485-493.

22. Buadu LD, Murakami J, Murayama S, et al. Breast lesions: correlation of contrast medium enhancement patterns on MR images with histopathologic findings and tumour angiogenesis. Radiology 1996; 200: 639-649.

23. Bird RE, Wallace TW, Yankaskas BC. Analysis of cancers missed at screening mammography. Radiology 1992; 184: 613-617.

24. Moss HA, Britton PD, Flower CD, Freeman AH, Lomas DJ; Warren RM. How reliable is modern breast imaging in differentiating benign from malignant breast lesions in the symptomatic population? Clin Radiol 1999; 54:676-82.

25. Berg WA, Campassi CI, Ioffe OB. Cystic lesions of the breast: sonographic-pathologic correlation. Radiology 2003; 227:183-91.

26. Kolb TM, Lichy J, Newhouse JH. Comparison of the performance of screening mammography, physical examination, and breast US and evaluation of factors that influence them: an analysis of 27,825 patient evaluations. Radiology 2002; 225:165-75.

27. Makes D Department of Radiology, Faculty of Medicine, University of Indonesia Ciptomangunkusumo General Hospital, Jakarta Biomed Imaging Interv J 2005; 1(1):e6-16

28. Tofts PS, Berkowitz B, Schnall MD. Quantitative analysis of dynamic Gd - DTPA enhancement in breast tumours using a permeability model. Magnetic Resonance Imaging 1995; 33:564-568.

29. Muller - Schimpfle M, Ohmenhauser K, Sand J, et al. Dynamic 3D - MR mammography: is there a benefit of sophisticated evalu- ation of enhancement curves for clinical routine? JMRI 1997; 7:236-240.

30. Herborn CU, Marincek B, Erfmann D, Meuli-Simmen C, Wedler $\mathrm{V}$, Bode-Lesniewska B, et al. Breast augmentation and reconstructive surgery: MR imaging of implant rupture and malignancy. Eur Radiol 2002; 12:2198-206.

31. Liberman L, Morris EA, Dershaw DD, Abramson AF, Tan LK. MR imaging of the ipsilateral breast in women with percutaneously proven breast cancer. AJR Am J Roentgenol 2003; 180:901-10

32. Obdeijn IM, Brouwers-Kuyper EM, Tilanus-Linthorst MM, Wiggers T, Oudkerk M. MR imaging-guided sonography followed by fineneedle aspiration cytology in occult carcinoma of the breast. AJR Am J Roentgenol 2000; 174:1079-84.

33. Liberman L, Morris EA, Kim CM, Kaplan JB, Abramson AF, Menell $\mathrm{JH}$, et al. MR imaging findings in the contralateral breast of women with recently diagnosed breast cancer. AJR Am J Roentgenol 2003; 180:333-41.

34. Kristoffersen Wiberg M, Aspelin P, Perbeck L, Bone B. Value of MR imaging in clinical evaluation of breast lesions. Acta Radiol 2002; 43:275-81.

35. Kerlikowske K, Grady D, Barclay J, Sickles EA, Ernster V. Effect of age, breast density, and family history on the sensitivity of first screening mammography. JAMA 1996; 276:38.

36. Koga S, Nakano S, Honma Y, Ogasawara N. [FDG-PET (positron emission tomography) in the detection of primary breast cancer and lymph nodes involvement] Nippon Rinsho. 2007 Jun 28; 65 Suppl 6:379-84. Japanese.

37. Ersoy R, Topaloglu O, Aydin C, Dirikoc A, Cakir B. Pituitary metastasis of breast cancer confirmed by fluorine-18 fluorodeoxyglucose positron emission tomography: a case report. J Endocrinol Invest. 2007 Jun; 30(6):532-3

38. Hartinger AE, Gagnon H, Guardo R. Accounting for hardware imperfections in EIT image reconstruction algorithms. Physiol Meas. $2007 \mathrm{Jul} ; 28(7): \mathrm{S} 13-27$.

39. Choi MH, Kao TJ, Isaacson D, Saulnier GJ, Newell JC. A reconstruction algorithm for breast cancer imaging with electrical impedance tomography in mammography geometry. IEEE Trans Biomed Eng. 2007; 54(4):700-10.

40. Halter RJ, Hartov A, Paulsen KD. Experimental justification for using 3D conductivity reconstructions in electrical impedance tomography. Physiol Meas. 2007; 28(7):S115-27. Epub 2007 Jun 26.

41. Mital M, Scott EP. Thermal detection of embedded tumors using infrared imaging. J Biomech Eng. 2007 Feb; 129(1):33-9.

42. Vincentis GD, Porfiri LM, Betti M, Filippi L, Remediani S, Santo GD, Zaccagnino P, Felice CD, Pieracci M, Cinti MN, Bennati P, Pellegrini R, Pani R. High-resolution scintimammography helps in differentiating benign from malignant findings in scintigraphic hot spots. Phys Med. 2006; 21 Suppl 1:87-90.

43. Gommans GM, van der Zant FM, van Dongen A, Boer RO, Teule GJ, de Waard JW. (99M) Technetium-sestamibi scintimammography in non-palpable breast lesions found on screening X-ray mammography.

44. Yamamoto A, Fukushima H, Okamura R, Nakamura Y, Morimoto T, Urata Y, Mukaihara S, Hayakawa K.Dynamic helical CT mammography of breast cancer. Radiat Med. 2006; 24(1):35-40.

45. Ternier F, Houvenaeghel G, Lecrivain F, Brigand BL, Margain D, Brunelle S, Stefano DD.Computed tomography in suspected local breast cancer recurrence. Breast Cancer Res Treat. 2006 Dec; 100(3):247-54.

46. Nakano S, Sakamoto H, Ohtsuka M, Mibu A, Sakata H, Yamamoto $M$. Evaluation and indications of ultrasound-guided vacuum-assisted core needle breast biopsy. Breast Cancer. 2007; 14 (3):292-6.

47. Weber WP, Zanetti R, Langer I, Dellas S, Zuber M, Moch H, Remmel E, Oertli D, Wight E, Marti WR. Mammotome: less invasive than ABBI with similar accuracy for early breast cancer detection. World J Surg. 2005; 29(4):495-9. 